\title{
Do adult focused anti-smoking campaigns have an impact on adolescents? The case of the Australian National Tobacco Campaign
}

\author{
V White, N Tan, M Wakefield, D Hill
}

Tobacco Control 2003;12(Suppl II):ii23-ii29

See end of article for authors' affiliations .......................

For correspondence: $\checkmark$ White, Centre for Behavioural Research in Cancer, Cancer Control Research Institute, The Cancer Council Victoria, 1 Rathdowne Street, Carlton, Vic 3053,

Australia;

vicki.white@

cancervic.org.au
Objectives: To examine adolescents' awareness of and response to an adult focused anti-smoking advertising campaign.

Design and setting: Data were obtained from two cross sectional surveys of adolescents. The first study, a national evaluation study, involved a telephone survey of a randomly selected sample of 400 14-17 year olds across Australia in 1998. The second study involved a survey of 3714 students aged 12-17 years, randomly selected from a probability sample of secondary schools in the Australian State of Victoria.

Main outcome measures: In both surveys, adolescents answered questions on their awareness of the advertising campaign and actions taken in response to the campaign. Adolescents in the national evaluation study also answered questions assessing knowledge of health effects of smoking, impact of the campaign on adolescents, and relevance of the campaign for adolescents and other groups. Responses for smokers and nonsmokers were examined.

Results: Among the national evaluation sample, $85 \%$ of adolescent smokers thought the campaign was relevant to them. Fifty three per cent indicated that the campaign had led some teenagers to at least try to quit and $85 \%$ thought it made smoking seem less cool and desirable. Among students who were established smokers the campaign generated quitting activity, with $27 \%$ cutting down the number of cigarettes they smoked and $26 \%$ having thought about quitting.

Conclusion: Results indicate that adolescents were very aware of this adult focused anti-smoking campaign and thought it relevant to them. The findings suggest that a graphic health effects cessation focused campaign may have been successful in promoting anti-smoking attitudes among adolescents.
$\mathrm{T}$ here has been some debate as to whether tobacco control programmes should focus primarily on preventing adolescents from smoking or encouraging adult smokers to quit. ${ }^{1-2}$ As most tobacco control programmes have limited resources, Hill believes they should focus on strategies that will lead to the biggest reduction in tobacco related harm. ${ }^{1}$ Because the health consequences of smoking are minimised if smokers quit before the age of $40,{ }^{3}$ it has been suggested that tobacco control programmes should emphasise strategies that encourage cessation among adults. ${ }^{1}$ Hill argues that this strategy will also impact on adolescent smoking, thus achieving the dual aims of tobacco control programmes. Adult campaigns that encourage quitting may influence adolescent smoking in several ways. Firstly, by reducing smoking among parents, such campaigns reduce the number of adolescents exposed to a major risk factor for smoking uptake..$^{4-5}$ Secondly, by making smoking a less desirable adult behaviour, adolescents' motivation to use tobacco as a signifier of adulthood will be reduced. Thirdly, as adolescents identify with adults and want to be treated as adults, they are highly likely to attend to the messages contained in adult focused anti-smoking campaigns.

Australia's National Tobacco Campaign (NTC) targeted smokers aged 18-40 and promoted a cessation message. The campaign used mass media advertising (predominantly television) to highlight some of the health consequences of smoking and aimed to get smokers to put quitting on today's agenda. To achieve this, new information about the health consequences of smoking relevant to smokers aged 18-40 years was presented in graphic television advertisements designed to evoke a negative visceral response (see Hill and Carroll this issue ${ }^{6}$ and Hassard ${ }^{7-8}$ for details of the campaign and advertisements). This approach was grounded in both health behaviour change theories (for example, health belief model $(\mathrm{HBM})^{9-10}$ and protection motivation theory $\left.(\mathrm{PMT})^{11}\right)$ and theories on the process of persuasion (for example, elaboration likelihood model $\left.(\text { ELM })^{12}\right)$, and the campaign aimed to change both attitudes towards smoking and smoking behaviours. The graphic images of the health consequences of smoking were used for several reasons. According to the HBM and PMT, if people perceive their current behaviour (smoking) as posing a severe threat to their wellbeing, and they know that a particular response will reduce this threat (that is, quitting), they are motivated to change their behaviour. Both the HBM and the PMT posit that graphic images such as those in the NTC advertisements help to increase both the perceived severity of the health risks associated with smoking and the likelihood of these events occurring. Thus, according to these two theories of behaviour change, the negative emotions evoked by the NTC advertisements should motivate people to change their smoking behaviours.

Attitudes are thought to consist of both affective and cognitive components, and models of the persuasion process, such as the ELM, suggest that attitude change can occur by changing either of these two components. The information about the particular health consequences of smoking depicted in the NTC advertisements provided the mechanism by which the cognitive component of the attitude towards smoking might be changed. The negative emotional response to the image in the advertisements provides the mechanism by which the affective component of the attitude towards smoking might be changed. Based on classical conditioning theory it is suggested

Abbreviations: NTC, National Tobacco Campaign; HBM, health belief model; PMT, protection motivation theory; ELM, elaboration likelihood model 
that by pairing an emotion with an attitude object (for example, smoking), the attitude can change in the direction of the emotion. ${ }^{13}$ Thus, by pairing smoking with negative emotions, as in the NTC advertisements, the attitudes of both smokers and nonsmokers towards smoking should become more negative.

Although adolescents were not the primary target group of the NTC, for the reasons stated above, it was expected that adolescents would attend to the campaign and that the dual components of the communication strategy would discourage uptake and promote cessation among adolescents. At the very least, it was hoped that adolescents would not reject the messages promoted by the NTC and that the campaign would not encourage experimentation with tobacco as a signifier of rebellion against an authority message from the conservative adult culture. Although research with adolescents suggested that there was no negative impact of the NTC advertisements on adolescents, ${ }^{14-15}$ it was not known if the campaign had a positive impact on adolescents' anti-smoking attitudes and/or their smoking behaviours. This paper investigates these issues.

As indicated above, the NTC advertisements were based on the assumption that by increasing the perceived severity of the risks associated with smoking and increasing individuals' perceived susceptibility to those risks by using fear appeals, people will be encouraged to quit smoking. There has been much debate as to the efficacy of fear appeals in relation to changing health related behaviours. ${ }^{16-20}$ It is widely believed that young people (for example, adolescents and young adults) do not have the same sense of death as older adults and that communication strategies emphasising death as a consequence of certain behaviours will be ridiculed and discarded by adolescents. Many studies aimed at increasing the likelihood that adolescents will adopt health promoting behaviours such as not smoking, safe driving, and safe use of alcohol have used fear appeals in their communication strategies. ${ }^{19}{ }^{21-23}$ In general, these studies have found that the use of high threat or fear appeals had little impact on adolescents' sense of vulnerability or their likelihood of adopting the recommended behaviours. However, recent work is suggesting that fear appeals are effective and can work with adolescents as long as they are accompanied by a message that suggests an effective response. ${ }^{19}$ Henley and Donovan ${ }^{17}$ have recently investigated whether young people respond differently to older people when presented with a variety of health messages about smoking that differ in their level of fear appeal. In this study, young people (16-25 year olds) and older people (40-50 year olds) were presented with messages about emphysema manipulated to present one of six different types of messages. The six different message types were: a control message that presented the facts about emphysema; a non-death fear message that presented information about disablement (dependence on oxygen) associated with emphysema; a death fear message, presenting information about the likelihood of death from emphysema; a death fear message that stressed the opportunities missed by premature death; and a death fear message that emphasised the impact of an individual's death on their loved ones. The study showed that non-death threat appeals and death threat appeals were equally effective with young people. Importantly, this study found that young people showed a greater response than older people to death threat appeals, suggesting that death appeals are effective at reaching young people. However, the study also found that the most effective messages for all age groups, and for males and females, were those using a non-death disablement appeal. Henley and Donovan concluded that fear appeals can influence young people's attitudes and behavioural intentions, at least regarding smoking. Their results also suggested that mass media campaigns that use non-death threat appeals focusing on disablement may be effective at reaching all segments of the market. As the NTC campaigns focused on presenting information about the impact of smoking on the body of 30-40 year old smokers (for instance, the clogging of arteries) rather than presenting death messages, they may be considered to present non-death disablement fear appeals. Given Henley and Donovan's results, ${ }^{17}$ there is good reason to expect that these sorts of advertisements may be effective with adolescents.

As described by Wakefield et a ${ }^{24}$ and Hill and Carroll, ${ }^{6}$ the first phase of the campaign ran between June and December 1997, when three main advertisements were broadcast. The second phase of the campaign ran between January and December 1998 and two new advertisements were added during this phase. The third phase of the campaign ran from January 1999 to December 2000, with another two new advertisements broadcast during 2000. In this paper we use data from two sources collected at two different phases of the campaign to examine whether the messages and strategies used in the NTC and designed to promote quitting among adults would also be attended to by adolescents. The influence of smoking status on response to the campaign is also examined. The first and primary data set for this study is taken from a national telephone survey of adolescents aged 14-17 conducted as part of the evaluation of the second phase of the NTC in November 1998. Findings from this study inform us of the immediate impact the campaign had on adolescents. The second data set comes from a survey of secondary school students in the Australian State of Victoria conducted between June and December 1999-during the third phase of the campaign. Findings from this study inform us of the continued impact of the campaign on adolescents' smoking behaviours.

\section{METHOD}

As indicated above, the first and primary data set for this study is taken from a national telephone survey of adolescents aged 14-17. This study assessed attitudes to smoking, intentions to smoke and, among smokers, quitting behaviours and is referred to as the national evaluation study. The second data set comes from a survey of a representative sample of Victorian secondary students aged 12-17 years. This survey asked students about their awareness of the campaign and whether they took any actions as a result of seeing the television advertisements. This data set is referred to as the Victorian secondary student's survey.

\section{National evaluation study: method and questionnaire,} sample size, and characteristics

The survey was conducted by telephone and used the electronic White Pages as the sampling frame. Adolescents from all State jurisdictions of Australia participated. Parents or guardians gave permission for their child to be invited into the study. Parents participating in the adult evaluation study with adolescents in the target age group (14-17 year olds) were asked if their adolescent child could participate in an interview. Interviews were obtained with adolescents from $50 \%$ of the households approached.

The questionnaire administered to adolescents contained approximately 49 questions. Participants were asked a series of questions assessing their awareness of the campaign, the impact of the campaign on the smoking behaviours of themselves and others, awareness of health consequences of smoking, and attitudes to smoking. Only those questions relevant to this paper are discussed in detail here. Participants were first asked about their awareness of advertising about health and whether they knew of any illnesses or damage caused by smoking. A series of questions about cigarette smoking was then asked to categorise participants into smokers, recent quitters, and nonsmokers. Smokers were asked to describe their feelings about being a smoker. All participants were asked about their likelihood of smoking a year from now. The next section of the questionnaire asked participants whether they agreed or disagreed with a number of opinion statements 
Table 1 Proportion of smokers and nonsmokers agreeing with campaign related beliefs (national evaluation study)

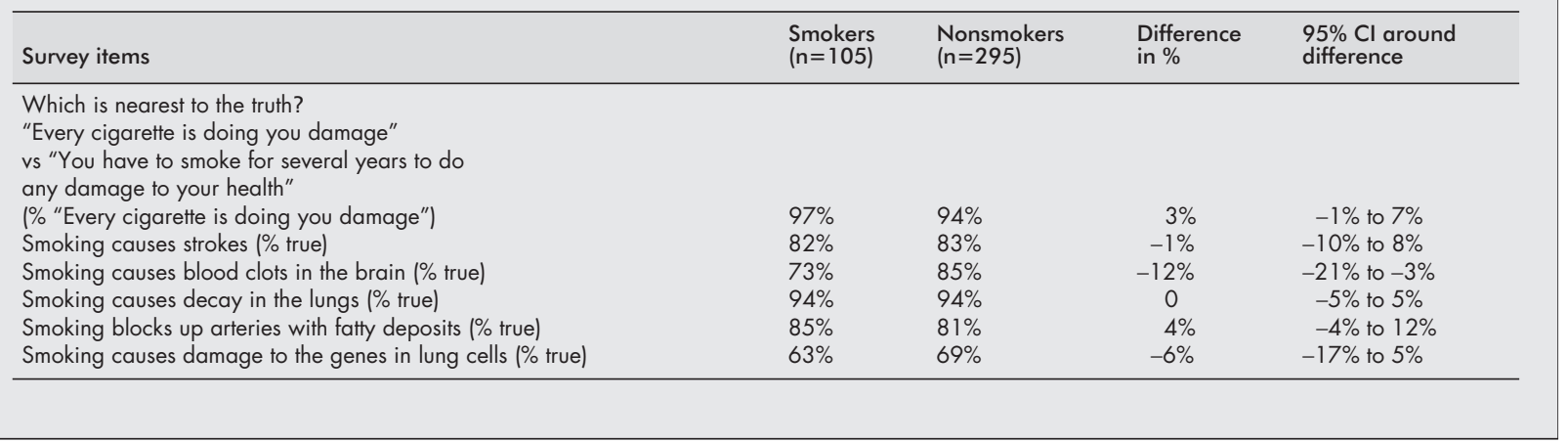

relating to smoking and health. Campaign advertising was then described to all participants and those who recognised the campaign advertising indicated whether they thought it was relevant to them. They were further asked for their appraisal of the campaign in terms of its impact on them and their friends. In addition, they were asked whether they thought the campaign would be effective in discouraging uptake of smoking or encouraging quitting in different age groups. Demographic information, including age, sex, and whether currently studying, was then collected.

\section{Sample}

A total of 400 teenagers were surveyed, with males and females equally represented in the sample (51\% females). Fifty per cent of the sample was aged 14-15. As might be expected, given the association between smoking and age, more smokers $(60 \%)$ than nonsmokers $(44 \%)$ were aged 16 or 17. Ninety per cent of the sample were full time students, $4 \%$ were studying part time, and $6 \%$ were not currently studying. More smokers $(20 \%)$ than nonsmokers $(1 \%)$ were no longer students $\left(\chi^{2}=54.3, \mathrm{df}=2, \mathrm{p}<0.01\right)$.

\section{Definitions of smoking status}

Respondents were asked if they had ever smoked a cigarette, if they had smoked in the past year, and if they currently smoked on a weekly basis. Forty nine adolescents (12\%) surveyed indicated they currently smoked at least weekly. A further 56 adolescents indicated that they had smoked in the past year but were not currently smoking at least weekly. The remaining 295 adolescents had either never smoked a cigarette or had not smoked cigarettes in the year prior to the survey. Adolescents who were current smokers and those who had smoked in the year prior to the survey would have been smoking at some point during the first two phases of the NTC. Given this, we expected current weekly smokers and adolescents who had smoked in the past year to respond similarly to the campaign. Further, given the relatively low numbers in these two individual groups, grouping them together gave more statistical power for analyses. This group was called the smoker group. As the NTC was as relevant to adolescents who had not smoked during the time it was running (those who smoked more than a year prior to the survey) as it was to never smokers, we expected these two groups to have a similar response to the campaign and therefore grouped them together for the purpose of analyses. This group is referred to as the nonsmoker group.

\section{Victorian secondary student's survey: method, questionnaire, sample size, and characteristics}

A survey of secondary school students was conducted in the State of Victoria throughout the second part of the school year in 1999. Schools approached for this survey were selected at random from the three education systems operating in Australia (Government, Catholic, and independent). Of the 70 secondary schools first selected to participate in the survey, 29 refused, giving a response rate of $59 \%$. From a sample of replacement schools, 26 schools agreed to take part in the study. Only three schools were unable to be replaced. Thus, a total of 67 secondary schools (96\% of the desired number) participated in the study. From these schools the researchers selected a random sample of 80 students from predetermined year levels. A total number of 4288 students participated in the study, giving a student participation rate of $80 \%$. Reasons for non-participation included being absent on the day of the survey, forgetting about the survey, or preferring to remain in class. Few students (less than $1 \%$ ) did not participate in the study because their parents refused permission or because they chose not to after hearing what the study was about.

Researchers administered the survey to students on the school premises. Students answered an anonymous 24 page core questionnaire assessing use of tobacco, alcohol, and illicit substances. Smoking questions assessed students' lifetime use of tobacco (students indicated if they had never smoked a cigarette; had a few puffs of a cigarette; had fewer than 10 cigarettes; had more than 10 cigarettes but less than 100 cigarettes; and smoked more than 100 cigarettes), use of tobacco in the past 12 months and past month (answered by indicating yes or no), and if they had smoked on any of the preceding seven days (students indicated the number of cigarettes smoked on each of these days, indicating 0 if no cigarettes were smoked). Students also answered questions assessing recall of health advertisements (yes or no response) and if they had seen some health advertising, indicated the advertising they had seen from a list of possible items that included tobacco, asthma, Traffic Accident Commission (road safety advertisements), diet, and skin cancer awareness. Students also indicated if they could recall the main tagline used in the NTC advertisements ("Every cigarette is doing you damage") by responding either yes or no, and responses to this question were used to indicate prompted recognition of the campaign. If they could recall the campaign, students were then asked to indicate whether they took any actions in response to the campaign from a list of possible responses, including doing nothing (response options shown in table 1).

\section{Sample}

A total of 4068 students aged between 12 and 17 years answered the questionnaire, and of these 3714 completed the questions on the NTC. Of the total sample, $49 \%$ were female and $69 \%$ were aged $\leqslant 15$.

\section{Definitions of smoking status}

Given the large sample size in this data set it was possible to determine more refined measures of smoking involvement for students than that used in the national evaluation study. For this data set we adopted the classification scheme of Choi et $a l,{ }^{25}$ who determined that adolescents who had smoked 100 cigarettes or more were established smokers and that those 
Table 2 Proportion of smokers and nonsmokers who had seen the NTC advertisements, agreeing with the statements on the impact of the campaign (national evaluation study)

\begin{tabular}{|c|c|c|c|c|c|}
\hline In your opinion, are the following statements true or false? & $\begin{array}{l}\text { Smokers } \\
(102)\end{array}$ & $\begin{array}{l}\text { Nonsmokers } \\
(283)\end{array}$ & $\begin{array}{l}\text { Total } \\
(385)\end{array}$ & $\begin{array}{l}\text { Difference } \\
\text { in } \%\end{array}$ & $\begin{array}{l}95 \% \mathrm{Cl} \text { around } \\
\text { difference }\end{array}$ \\
\hline \multicolumn{6}{|l|}{ This campaign has: } \\
\hline Discouraged some friends from smoking & $32 \%$ & $36 \%$ & $33 \%$ & $-4 \%$ & $-15 \%$ to $7 \%$ \\
\hline Makes smoking seem appealing to some teenagers & $23 \%$ & $14 \%$ & $16 \%$ & $9 \%$ & $0 \%$ to $18 \%$ \\
\hline Led some teenagers I know to quit or try to quit & $59 \%$ & $50 \%$ & $53 \%$ & $9 \%$ & $-2 \%$ to $20 \%$ \\
\hline Makes smoking seem less cool and desirable & $84 \%$ & $86 \%$ & $85 \%$ & $-2 \%$ & $-10 \%$ to $6 \%$ \\
\hline
\end{tabular}

who had smoked in the past month were currently involved with smoking. The smoking involvement categories used were: current established smokers (students who had smoked more than 100 cigarettes and had smoked in the previous month); ex-established smokers (students who had smoked more than 100 cigarettes in their lifetime but had not smoked in the past month); recent experimenters (students who had smoked in the past month but had not smoked more than 100 cigarettes); non-recent experimenters (students who had not smoked more than 100 cigarettes and had not smoked in the past month); and never smokers (students who had never smoked a cigarette). According to these definitions, $41 \%$ were never smokers, 32\% were non-recent experimenters, $14 \%$ were recent experimenters, $1 \%$ were ex-established smokers, and $12 \%$ were current established smokers.

\section{Statistical analyses}

Both data sets were weighted to correct for any over or under sampling. For the national evaluation sample the weighting factors corrected for over or under sampling of adolescents from the different State jurisdictions. In the student sample the weighting factors were based on age, sex, and education sector (Government, Catholic, or independent schools) and State. The proportions of adolescents responding to the different questions are reported and $\chi^{2}$ tests of association were used to determine if smokers' perceptions of the campaign and response to the campaign were significantly different from those of nonsmokers. Ninety five per cent confidence intervals $(95 \% \mathrm{CI})$ are reported for proportions discussed in the text. A statistical criterion of $p<0.05$ was used to determine statistical significance.

\section{RESULTS}

\section{Awareness of the NTC advertisements}

National evaluation study

Unprompted recall of advertising about tobacco in the past three months for the national evaluation sample was high, with $60 \%$ (95\% CI $55 \%$ to $65 \%$ ) of adolescents being aware of advertising about the health effects of smoking. Adolescents who had seen health related advertising were more likely to mention having seen anti-smoking advertising compared with other health related advertisements. For instance, 60\% (95\% CI 55\% to $65 \%$ ) of adolescents reported that they saw anti-smoking advertising compared with $18 \%$ (95\% CI 14\% to $22 \%$ ) who were aware of weight loss advertising, 15\% (95\% CI $12 \%$ to $18 \%$ ) aware of advertising for a healthy lifestyle, $6 \%$ (95\% CI $4 \%$ to $8 \%$ ) who were aware of advertising for dairy products and $4 \%$ (95\% CI $2 \%$ to $6 \%$ ) vitamins. Other types of health related advertising (for example alcohol, illicit drugs, and drink driving) were mentioned by less than $4 \%$ of the sample. Prompted recognition of the NTC advertisements was high among adolescents in this sample. Three months after the end of phase two of the NTC $90 \%$ (95\% CI $87 \%$ to $92 \%$ ) of adolescents surveyed ( $88 \%$ (95\% CI $84 \%$ to $92 \%$ ) nonsmokers and $94 \%$ (95\% CI $89 \%$ to $99 \%$ ) smokers) recognised the campaign by its slogan "Every cigarette is doing you damage".

\section{Victorian student survey}

Unprompted recall of advertising about tobacco in the past year for the Victorian student sample was also high. Among the student sample $80 \%$ (95\% CI $79 \%$ to $81 \%$ ) indicated they had seen anti-smoking advertising in the previous year in response to a question asking about seeing health advertising in general. Recall of anti-smoking advertisements was higher than recall of other health campaigns. Among Victorian students, after tobacco the next most commonly recalled health campaign was the Traffic Accident Commission road safety advertisements (69\% (95\% CI 68\% to $70 \%)$ ), followed by skin cancer $(59 \%(95 \%$ CI $57 \%$ to $61 \%))$, diet $(47 \%$ (95\% CI $45 \%$ to $49 \%)$ ), osteoporosis ( $42 \%$ (95\% CI $40 \%$ to $44 \%)$ ), and asthma and immunisation (33\% (95\% CI $31 \%$ to $35 \%)$ ). Recognition of the NTC campaign's tagline was high, with 97\% (95\% CI $96 \%$ to $98 \%$ ) of $12-17$ year old students (96\% (95\% CI $95 \%$ to $97 \%$ ) never smokers and $98 \%$ (95\% CI $97 \%$ to $99 \%$ ) current established smokers) recognising the advertisements by the slogan "Every cigarette is doing you damage".

\section{Adolescent beliefs about smoking: national evaluation study}

Adolescents in the national evaluation study were asked whether they thought a number of statements corresponding to the main messages of the NTC advertisements were true or not. The proportion of smokers and nonsmokers agreeing with each statement is shown in table 2 . In general, a large majority of adolescent smokers and nonsmokers agreed with the statements about campaign related beliefs and there was little difference in the proportion of smokers and nonsmokers agreeing with these statements. The exception to this was for the statement "smoking causes blood clots in the brain", where significantly more nonsmokers $(85 \%)$ than smokers $(73 \%)$ agreed with this statement (difference in proportion, $12 \%$; $95 \%$ CI $3 \%$ to $21 \%$ ).

In response to a series of questions asking about the relevance of the campaign in the national evaluation survey, $54 \%$ (95\% CI $48 \%$ to $60 \%$ ) of nonsmokers and only $16 \%(95 \%$ CI $9 \%$ to $23 \%$ ) of smokers thought the campaign was not relevant to them $\left(\chi^{2}=44.1, \mathrm{df}=1, \mathrm{p}<0.01\right)$. When asked about the relevance of the campaign to specific groups, $67 \%$ (95\% CI $62 \%$ to $72 \%$ ) thought it relevant to anyone who might smoke, $89 \%$ (95\% CI $86 \%$ to $92 \%$ ) thought it relevant to primary school students, $77 \%$ (95\% CI $73 \%$ to $81 \%$ ) to secondary school students, $82 \%$ (95\% CI $78 \%$ to $86 \%$ ) to young smokers and $85 \%$ (95\% CI $82 \%$ to $88 \%$ ) to older smokers. The proportion of smokers and nonsmokers believing the campaign was relevant to these groups did not differ significantly.

Adolescents were also asked whether they agreed with statements suggesting that the campaign had some impact on the smoking behaviours of friends and other teenagers. Responses to these questions are summarised in table 3.

The proportion of smokers and nonsmokers indicating that the campaign had discouraged some of their friends from smoking was similar. Smokers (59\%) were more likely than nonsmokers $(50 \%)$ to indicate that the campaign had led some acquaintances to at least try to quit. However, this 
Table 3 Discussions about smoking and health generated in response to the campaign for smokers and nonsmokers who had seen the campaign (national evaluation study)

\begin{tabular}{lllrr}
\hline $\begin{array}{l}\text { Whether campaign caused any discussions about } \\
\text { smoking and health? }\end{array}$ & $\begin{array}{l}\text { Smokers } \\
(\mathrm{n}=101)\end{array}$ & $\begin{array}{l}\text { Nonsmokers } \\
(\mathrm{n}=283)\end{array}$ & $\begin{array}{l}\text { Difference in } \\
\text { proportions }\end{array}$ \\
\hline At home & $36 \%$ & $30 \%$ & $\begin{array}{l}95 \% \mathrm{Cl} \\
\text { around difference }\end{array}$ & $-5 \%$ to $17 \%$ \\
In school & $37 \%$ & $57 \%$ & $-20 \%$ & $-31 \%$ to $-9 \%$ \\
Among friends & $54 \%$ & $44 \%$ & $10 \%$ & $-1 \%$ to $21 \%$ \\
\hline
\end{tabular}

difference was not significant (difference 9\%; 95\% CI 2\% to $20 \%$ ). Over three quarters of smokers and nonsmokers thought the campaign had made smoking less cool and desirable. Slightly more smokers (16\%) than nonsmokers (14\%) thought the campaign had made smoking more appealing to some teenagers; however, this difference was not significant (difference 2\%; 95\% CI $-6 \%$ to $10 \%$ ).

Participants were also asked if the campaign generated any discussions about smoking and health in their home, school, and among their friends. Table 4 shows that slightly more teenage smokers than nonsmokers were discussing smoking and health at home and with their friends. Although these differences were not statistically significant, more nonsmokers $(57 \%$ (95\% CI $51 \%$ to $63 \%)$ ) than smokers (37\% (95\% CI $28 \%$ to $46 \%)$ ) reported discussing the campaign at school $\left(\chi^{2}=12.8, \mathrm{df}=1, \mathrm{p}<0.01\right)$.

\section{Response to the NTC: Victorian student sample}

Adolescents in the student sample who had seen the NTC advertisements were asked if they did anything in response to the campaign and could select items from the list shown in Table 1. More current established smokers (63\% (95\% CI 59\% to $67 \%)$ ), ex-established smokers (61\% (95\% CI $45 \%$ to $77 \%)$ ), and recent experimenters (66\% (95\% CI 62\% to 70\%)) had taken some action in response to the campaign than had never smokers $(53 \%$ (95\% CI $50 \%$ to $56 \%))\left(\chi^{2}=40.13, \mathrm{df}=4, \mathrm{p}\right.$ $<0.01)$. The campaign generated quitting activity among current established smokers, with $18 \%$ (95\% CI $14 \%$ to $22 \%$ ) saying they had tried to give up smoking, $27 \%$ (95\% CI $23 \%$ to $31 \%$ ) saying they had cut down the number of cigarettes they smoked, and $26 \%$ (95\% CI $22 \%$ to $30 \%$ ) saying they had thought about quitting. Twenty two per cent $(95 \%$ CI $8 \%$ to $36 \%$ ) of ex-established smokers and $10 \%$ (95\% CI $8 \%$ to $12 \%$ ) of non-recent experimenters indicated they gave up smoking in response to the campaign. Although 6\% (95\% CI $4 \%$ to $8 \%$ ) of current established smokers indicated they had given up smoking in response to the campaign, as they had smoked in the month prior to the survey these students must have relapsed. The NTC prompted about 12\% (95\% CI $11 \%$ to $13 \%$ ) of students to talk to their friends about smoking, while $10 \%$ (95\% CI $9 \%$ to $11 \%$ ) indicated they talked to their parents about quitting in response to the campaign. Three per cent of current established smokers (95\% CI $1 \%$ to $5 \%$ ), 5\% of recent experimenters (95\% CI $3 \%$ to $7 \%$ ), and $1 \%$ of nonsmokers (95\% CI $0.5 \%$ to $1.5 \%$ ) indicated they had tried smoking in response to the campaign. Just over $30 \%$ of never smokers and non-recent experimenters indicated that the campaign had prompted them to talk to someone other than their friends and parents about quitting.

\section{Impact of the NTC on adolescents' thoughts about smoking and quitting national evaluation survey}

Only those adolescents who were current smokers in the national evaluation survey were asked if they thought the campaign had made them more or less likely to quit smoking. There were 49 current smokers, and around two thirds (67\% (95\% CI $54 \%$ to $80 \%)$ ) indicated that the campaign had made it more likely they would quit. Nonsmokers who had seen the campaign were asked if the advertisements had made it easier for them to stay a nonsmoker and $86 \%$ (95\% CI $82 \%$ to $90 \%$ ) indicated this was the case.

\section{DISCUSSION}

Despite the fact that the NTC was aimed at 18-40 year olds and had a strong cessation message, the results presented here suggest that the campaign had some impact on adolescents. Campaign advertising was seen and remembered by teenagers irrespective of their smoking status. There was strong agreement with campaign related beliefs about smoking and health and a significant proportion of adolescent smokers or recent quitters indicated that they had made a quit attempt or had cut down their consumption of cigarettes in response to the campaign.

Before discussing the implications of the study, several limitations need to be noted. We presented data from two cross sectional studies, one consisting of a random sample of Australian adolescents conducted after the second phase of

Table 4 Of those who saw advertisements, actions taken in response to NTC advertisements as reported by secondary school students in 1999 (Victorian student study)

\begin{tabular}{|c|c|c|c|c|c|}
\hline \multirow{2}{*}{$\begin{array}{l}\text { Did you do anything as a result of seeing } \\
\text { the advertisements? }\end{array}$} & $\begin{array}{l}\text { Current } \\
\text { established } \\
\text { smokers }\end{array}$ & $\begin{array}{l}\text { Ex-established } \\
\text { smokers }\end{array}$ & $\begin{array}{l}\text { Recent } \\
\text { experimental } \\
\text { smokers }\end{array}$ & $\begin{array}{l}\text { Non-recent } \\
\text { experimental } \\
\text { smoker }\end{array}$ & Never smoked \\
\hline & $(436)$ & (36) & $(494)$ & (1 104) & $(1367)$ \\
\hline Gave up smoking & $6 \%$ & $22 \%$ & $8 \%$ & $10 \%$ & $N / A$ \\
\hline Tried to quit & $18 \%$ & $6 \%$ & $11 \%$ & $3 \%$ & $2 \%$ \\
\hline Cut down number of cigarettes smoked & $27 \%$ & $6 \%$ & $22 \%$ & $4 \%$ & $2 \%$ \\
\hline Rang quit line & $3 \%$ & $3 \%$ & $2 \%$ & $1 \%$ & N/A \\
\hline Thought about quitting & $26 \%$ & $11 \%$ & $10 \%$ & $2 \%$ & $\mathrm{~N} / \mathrm{A}$ \\
\hline Talked to parents about quitting & $6 \%$ & $22 \%$ & $9 \%$ & $13 \%$ & $10 \%$ \\
\hline Talked to friends about quitting & $8 \%$ & $19 \%$ & $14 \%$ & $14 \%$ & $11 \%$ \\
\hline Tried smoking & $3 \%$ & $6 \%$ & $5 \%$ & $1 \%$ & $1 \%$ \\
\hline Told someone else to quit & $13 \%$ & $28 \%$ & $25 \%$ & $34 \%$ & $32 \%$ \\
\hline Nothing & $42 \%$ & $47 \%$ & $39 \%$ & $50 \%$ & $57 \%$ \\
\hline
\end{tabular}


the NTC and the other a survey of students in the State of Victoria conducted during the third phase of the campaign. There were no baseline data, nor were there data from a control group, so we cannot say for certain whether the campaign directly influenced adolescents' intentions to stop smoking and/or had an impact on their quitting behaviours. However, we believe the data on campaign awareness and response to the campaign from both data sources are of interest and provide some insight into the impact of adult focused fear based anti-smoking campaigns on adolescents. We argue that the data from both sources provide a triangulation of evidence suggesting that adult anti tobacco campaigns can have an impact on attitudes and awareness of campaigns among adolescents. We note also that while we have focused on the television advertisements of the NTC in discussion of this campaign's communication strategy, other media were used to promote these messages ${ }^{6}$ and price increases were observed in cigarettes as a result of taxation changes and increases. ${ }^{26}$ In addition, other State based tobacco control strategies were implemented over the period of study, including campaigns and education efforts and changes in legislation restricting smoking in public spaces, and restricting the sale of cigarettes to those aged over 18 years. The impact of the campaign on adolescents' awareness might be due to the comprehensiveness of tobacco control efforts, not just the NTC advertisements. However, we note that the television advertisements formed the centrepiece of the campaign and the messages promoted in these advertisements were echoed in other elements of the NTC. ${ }^{6}$

A comparison of how adolescents responded to the NTC compared with adults has been made by Tan $\mathrm{et} \mathrm{l}^{27}$ and further comparisons can be made by examining Wakefield et al's $\mathrm{s}^{24}$ results with those presented here. Tan $e a^{27}$ showed that the responses of adolescent smokers and recent quitters to the NTC were comparable to, and in some respects more positive than, those of adult smokers and recent quitters. While $71 \%$ of adult smokers and recent quitters agreed with the statement that smoking causes blood clots in the brains,${ }^{24} 73 \%$ of adolescent smokers and recent quitters agreed with this statement. Anti tobacco campaigns that target adult smokers seem to be effective in getting anti tobacco messages to adolescents.

Our results are consistent with findings from other research. A survey of 15-17 year olds in South Australia indicated that advertisements from the NTC made smokers more uncomfortable about their smoking and more likely to think about quitting than an anti-smoking advertisement that specifically targeted adolescents. ${ }^{15}$ In an audience response study with a follow up component, Wakefield $e t a^{28}$ found that the "artery" advertisement was one of the most recalled, discussed, and thought about out of a sample of 37 anti-smoking advertisements to which adolescents were exposed.

It is well established that people selectively attend to information that supports their current behaviours and attitudes. ${ }^{29}$ This selective attention has also been found for consumers in relation to product information. ${ }^{30}$ This body of work suggests that any campaign that promotes smoking cessation is more likely to be attended to by nonsmokers or ex-smokers than smokers. In contrast to this expectation, the results presented here suggest that adolescent smokers and nonsmokers attended to the campaign equally. Similar proportions of smokers and nonsmokers were aware of the campaign and similar proportions of smokers and nonsmokers agreed with messages promoted by the campaign. Where there were differences in the responses of nonsmokers and smokers to the campaign these were as might be expected if the campaign was successful at getting quitting on the agenda of smokers. Smokers were more likely than nonsmokers to think the campaign was relevant to them, to do something in response to the campaign, and to talk about smoking among their friends.

The advertisements for the NTC were designed to evoke strong negative emotions towards smoking. The effectiveness of this approach is supported by a recent review that showed that high fear messages in public health campaigns are effective as long as the message is accompanied by a high self efficacy message. ${ }^{19}$ However, recent work from the United States suggests that although these types of advertisements might be popular with adolescents, their efficacy in reducing adolescent smoking intentions and behaviours is unclear. ${ }^{18}$ In a study by Pechmann and Reibling ${ }^{31}$ adolescents indicated their intention to smoke before and after viewing examples of one of seven different types of anti-smoking advertisements. The seven advertising types viewed were: death and disease, cosmetics (emphasised immediate consequences of smoking-smell and risk of social rejection), endangers family (stressed harm done by passive smoking and early death of family members), negative life circumstances (presented smokers as unattractive), refusal skills (emphasised refusal skills), marketing (disclosed tactics to sell tobacco), and selling death and disease (vilifying tobacco industry). The advertisements found to be most effective at reducing intention to smoke were the "endangers family", "negative life circumstances", and "refusal skills" types. This study found that although the disease and death advertisements increased adolescents' perceptions about the severity of the health risks associated with smoking, they had no impact on intention to smoke.

There are similarities and differences in the findings of Pechmann and Reibling ${ }^{31}$ and Henley and Donovan. ${ }^{17}$ Like Pechman and Reibling, Henley and Donovan found that fear appeals based on messages about what will be missed if you die from a smoking related illness were effective at increasing intentions to quit among younger people. However, Henley and Donovan also found that the disablement message was effective at increasing intentions to stop smoking. The present study suggests that a well funded, multi-pronged, anti-smoking campaign that uses advertisements evoking strong negative emotions is effective at taking the antismoking message to adolescents, decreasing intention to smoke, and encouraging quitting behaviours. Differences in the conclusions about the effectiveness of high fear appeal advertisements in reducing smoking among adolescents need to be investigated. The different conclusions are unlikely to reflect differences between United States and Australian adolescents, given Wakefield et al's findings of consistency in responsiveness to a range of anti-smoking advertisments between youth in these two countries. ${ }^{28}$ However, these different conclusions might relate to differences in the quality of the advertisements shown to adolescents, the difference between viewing advertisements in the absence of a campaign, or a combination of these reasons and requires further study.

Overall, the results reported here show that an adult oriented cessation campaign that used graphic advertising was received positively by adolescents and that adolescent smokers thought it was relevant to them. These encouraging findings suggest possible areas to explore for future campaigns targeting this age group. These include prevention, scope for new learning about smoking and health issues, building upon good intentions to quit, and the influence of peers.

\section{ACKNOWLEDGEMENTS}

This work was funded by the Commonwealth Department of Health and Ageing and The Cancer Council Victoria. The Victorian Department of Human Services contributed funds for the collection of data from Victorian secondary students.

\section{DISCLOSURE}

Melanie Wakefield is a senior editor of Tobacco Control. She was excluded from editor-reviewer correspondence and was not involved in the editorial decision making process for this manuscript. 


\section{Authors' affiliations}

V White, M Wakefield, D Hill, Centre for Behavioural Research in Cancer, Cancer Control Research Institute, The Cancer Council Victoria, Australia

N Tan, Centre for Clinical Research in Cancer, The Cancer Council Victoria, Australia

\section{REFERENCES}

1 Hill D. Why we should tackle adult smoking first. Tob Control 1999;8:333-5

2 Myers ML. Adults versus teenagers: a false dilemma and a dangerous choice. Tob Control 1999;8:336-8.

3 Peto R, Lopez A, Liu B. Global tobacco mortality: monitoring the growing epidemic. In: Lu R, Mackay J, Niu S, et al, eds. Tobacco the growing epidemic. Proceedings of the Tenth World Conference on Tobacco or Health, Beijing, China, 24-28 August 1997. London: Springer, 2000.

4 Conrad K, Flay B, Hill D. Why children start smoking cigarettes: predictors of onset. British Journal of Addiction 1992;87:1711-24.

5 Tyas SL, Pedersen LL. Psychosocial factors related to adolescent smoking: a critical review of the literature. Tob Control 1998;7:409-20.

6 Hill D, Carroll T. The Australian National Tobacco Campaign. Tob Control 2003;12(suppl II):ii9-14.

7 Hassard K, ed. Australia's National Tobacco Campaign: evaluation report volume one. Canberra: Commonwealth Department of Health and Aged Care, 1999. www.health.gov.au/pubhlth/publicat/document/ metadata/tobccamp.htm

8 Hassard K, ed. Australia's National Tobacco Campaign: evaluation report volume two. Canberra: Commonwealth Department of Health and Aged Care, 2000. www.health.gov.au/pubhlth/publicat/document/ metadata/tobccamp_2.htm

9 Janz N, Becker M. The Health Belief Model: a decade later. Health Education Quarterly 1984;1 1:1-47.

10 Strecher V, Rosenstock I. The Health Belief Model. In: Glanz K, Lewis F, Rimer B, eds. Health behaviour and health education: theory, research and practice. 2nd end. San Fransisco: Jossey-Bass, 1997:41-59.

11 Prentice-Dunn S, Rogers R. Protection Motivation Theory and preventive health: beyond the Health Belief Model. Health Education Research 1986:1:153-61.

12 Petty R, Cacioppo J. The elaboration likelihood model of persuasion. In: Berkowitz L, ed. Advances in experimental social psychology. Vol 19 Orlando, Florida: Academic Press, 1986:123-205

13 Breckler S. Emotion and attitude change. In: Lewis M, Haviland J, eds. Handbook of emotions. New York: The Guilford Press, 1993:461-73.

14 Borland R, Boulter J, McKenzie J, et al. National Tobacco Campaign advertisement pre-testing with secondary school students [Unpublished report]. Melbourne: Centre for Behavioural Research in Cancer, Anti-Cancer Council of Victoria, 1999.
15 Wakefield M Miller C, Roberts L. Comparison of the National Tobacco Campaign with a youth targeted South Australian campaign. In: Hassard K, ed. Australia's National Tobacco Campaign: evaluation report volume one. Canberra: Commonwealth Department of Health and Aged Care, 1999. www.health.gov.au/pubhlth/publicat/document/metadata/ tobccamp.htm

16 Montazeri A, McEwen J. Effective communication: perception of two anti-smoking advertisements. Patient Education and Counseling 1997;30:29-35

17 Henley N, Donovan R. Young people's response to death threat appeals: do they really feel immortal? Health Education Research: Theory and Research 2003;18:1-14.

18 Biener L. Anti-tobacco advertisements by Massachusetts and Philip Morris: what teenagers think. Tob Control 2002; 11 (Suppl ii):ii43-6

19 Witte K, Allen M. A meta-analysis of fear appeals: implications for effective public health campaigns. Health Educ Behav 2000;1:591-615.

20 Hastings G, McFadyen L. The limitations of fear messages. Tob Control 2002;11:73-5.

21 Sutton S, Hallet R. Understanding the effects of fear-arousing communications: the role of cognitive factors and amount of fear aroused. J Behav Med 1988;11:353-60.

22 Taubman-Ben-Ari $O$. The effect of reminders of death on reckless driving: a terror management perspective. Current Directions in Psychological Science 2000;9:196-9.

23 Henley N, Donovan R. Threat appeals in social marketing: death as a 'special case'. International Journal of Nonprofit and Voluntary Sector Marketing 1999;4:1-20

24 Wakefield $M$, Freeman J, Donovan R. Recall and response of smokers and recent quitters to the Australian National Tobacco Campaign. Tob Control 2003;12(Suppl II):ii 15-22.

25 Choi WS, Gilpin EA, Farkas AJ, et al. Determining the probability of future smoking among adolescents. Addiction 2001;96:313-23.

26 Scollo M, Younie S, et al. Impact of tobacco tax reforms on tobacco prices and tobacco use in Australia. Tob Control 2003;12/Suppl II):ii59-66.

27 Tan N, Montague M, Freeman J. Impact of the National Tobacco Campaign: comparison between teenage and adult surveys. In: Hassard K, ed. Australia's National Tobacco Campaign: evaluation report volume two. Canberra: Commonwealth Department of Health and Aged Care, 2000.

28 Wakefield M, Durrant R, Terry-McElrath Y, et al. Appraisal of anti-smoking advertisements by youth at risk for regular smoking: a comparative study in the United States, Australia, and Britain. Tob Control 2003; 12(Suppl II):ii82-6.

29 Festinger L. Conflict, decision and dissonance. Stanford, CA: Stanford University Press, 1964

30 Alba J, Hutchinson W. Dimensions of consumer expertise. Journal of Consumer Research 1987;13:411-54.

31 Pechmann C, Reibling E. Planning for an effective anti-smoking mass media campaign targeting adolescents. J Public Health Management and Practice 2000;6:80-94. 